This item was submitted to Loughborough's Research Repository by the author.

Items in Figshare are protected by copyright, with all rights reserved, unless otherwise indicated.

\title{
Queer bodies: sexualities, genders and fatness in physical education [book review]
}

PLEASE CITE THE PUBLISHED VERSION

http://dx.doi.org/10.1080/13573322.2013.737167

PUBLISHER

(C) Taylor \& Francis (Routledge)

VERSION

SMUR (Submitted Manuscript Under Review)

LICENCE

CC BY-NC-ND 4.0

\section{REPOSITORY RECORD}

Hill, Joanne L.. 2019. "Queer Bodies: Sexualities, Genders and Fatness in Physical Education [book Review]". figshare. https://hdl.handle.net/2134/12217. 
This item was submitted to Loughborough's Institutional Repository (https://dspace.lboro.ac.uk/) by the author and is made available under the following Creative Commons Licence conditions.

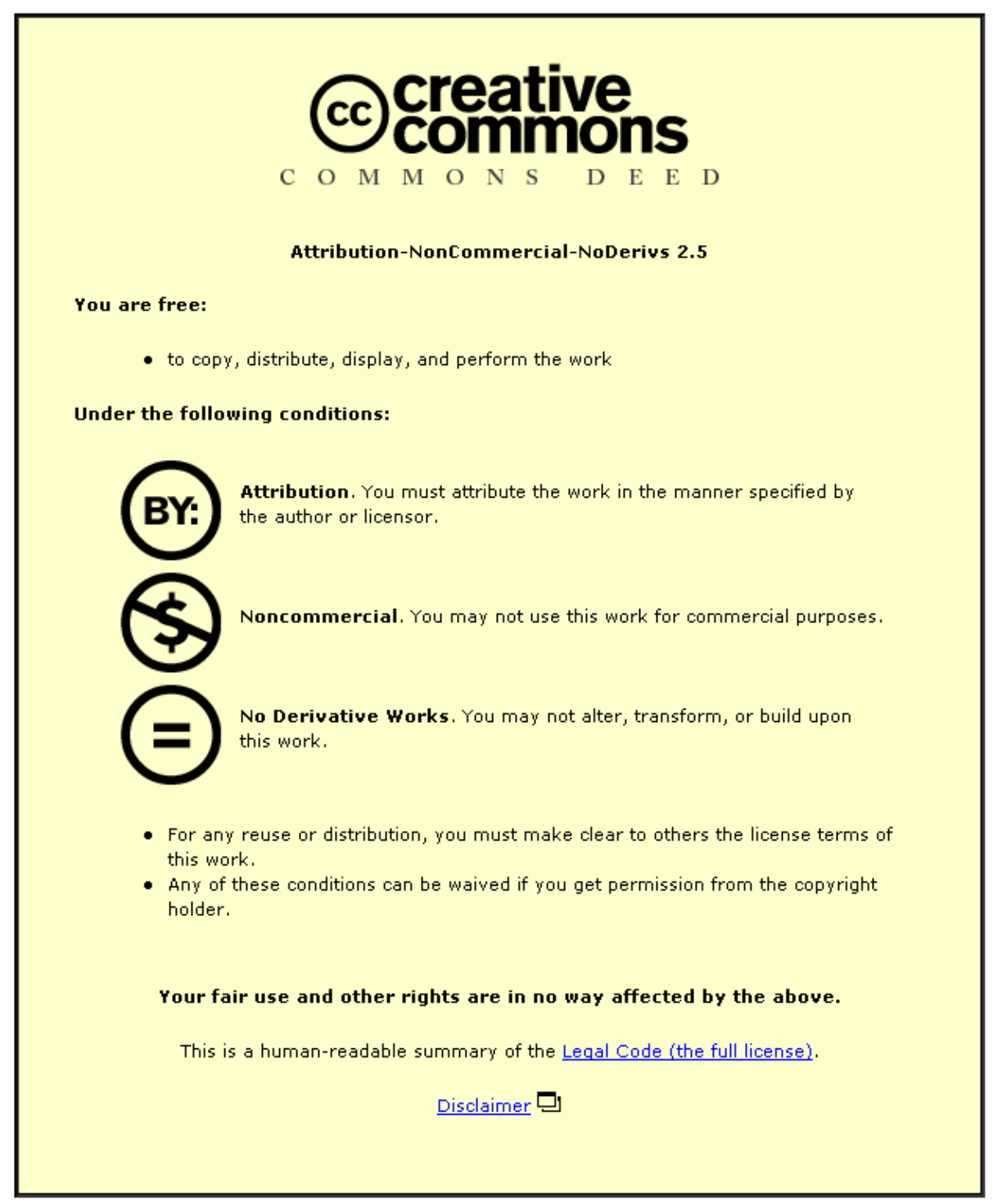

For the full text of this licence, please go to: http://creativecommons.org/licenses/by-nc-nd/2.5/ 
Notice: This is the author's version of a book review published in Sport, Education and Society, 2012 (an iFirst article). The review appears here in its pre-publication format in lieu of the publisher's version of record. The published review can be found at http://www.tandfonline.com/doi/abs/10.1080/13573322.2013.737167

\section{Queer Bodies: sexualities, genders and fatness in physical education}

Heather Sykes

New York, Peter Lang

$£ 22.00$ (pbk), $157 \mathrm{pp}+\mathrm{xi}$

ISBN: 978-1433111617

There is a significant and still growing emphasis on research from a social justice or equity perspective in physical education and sport, predominantly on gender but also concerning ethnicity, class or sexuality. Specifically, it has been consistently identified that sport and physical education have a heterosexual and masculine bias which affects the development of identity or subjectivity. In Queer Bodies, Heather Sykes takes up these familiar lenses and applies them to exploration of the physical education experiences of a number of transgender, gay and lesbian, and fat or overweight adults as they recall their youth ranging from the 1950 s to the 2000s. The focus of Queer Bodies is on the retelling of incidents and experiences in physical education that were told to research project the qBody Project by a number of Canadian adults as they looked back on their school days. The aim of the book is to examine how marginalisation has been experienced, but also how normative forces have been resisted or avoided by those for whom 'anxieties about the body, normalcy, athleticism and health' (p. 1) can transform into heterosexism, transphobia and fat phobia.

The poststructural and gender theory providing a basis to the book is outlined briefly at the outset. Sykes draws on sociological and poststructuralist thought centring bodies and embodiment in ideas of subjectivity and also seeks to bring 'psychic aspects' into social understandings of PE, looking beyond. The central theory around which the book is structured to explore is that of "phantasy". This is succinctly defined as "imaginaries of normative bodies" that "normalize particular constellations of whiteness, able-bodiedness, masculinity and athleticism' (p. 90). Widely held notions of the struggles of adolescence and changing bodies are forgotten in PE and participants felt that other students were able to do and say whatever they wanted. Sykes deconstructs the complexity of concepts of masculinity, militarism and nationalism, heterosexuality, pleasure, whiteness within the environments of physical education as they contribute to the phantasy and imaginary of normality. To be normal is an achievement, it means to stop the hidden inside from leaking out - being a coherent body with boundaries and certainties. With fat bodies, Sykes tells us, the boundaries 
are not defined, neither are they productive. She also argues that homophobia and transphobia stem from not being able to tell who is like oneself and who is other. Recalling the gaze and visual economy, Sykes considers the visibility of queer bodies to be behind the disgust.

The presence of queer bodies threatens to expose which phantasies are being sustained in supposedly fun, innocent, everyday, universal games and activities (p. 117).

Chapters 2, 3, and 4 focus on the participants' stories, in turn offering analysis from interviews with gay and lesbian, trans/intersex, and fat individuals. In Chapter 5, the participants' attention moves to their identifications with or against their physical education teachers. Sykes 'complicates the conversation about curriculum reforms in physical education, about how to value, respect and educate students with "queer bodies"' (p. 5). The opening chapter indicates that the book is aimed at physical educators - perhaps those who may recognise in this book their own practices. Despite the research for this book being carried out in Canada, a potentially predominant US audience is recognised through the highlighting of a number of policy examples from the USA.

In Chapter 2, Sykes asks why heterosexuality has become the only acceptable sexual identity especially within physical education, and why heterosexuality is so associated with masculinity and athleticism. Sykes takes familiar stories about heterosexism and homophobia in PE and school and offers further critical analysis. Here we consider that heterosexuality is the original sexuality from which all others deviate, that heterosexuality is normal, but also has to work at being seen as normal; hence a constant proving of heterosexuality. Sexuality is also tied to body size and strength, plus impenetrability that Sykes associates with nationalism. Here it is argued that fat phobia becomes evident in similar ways to homophobia, where heterosexism demands a fixed body shape that defines masculine from feminine.

While other research into heterosexism and homophobia can be found in the field, Sykes argues that little has been conducted with trans and intersex students. The difficulties for trans and intersex students in living their gender identities during physical education should implicate everyone in conversations about doing gender (as male or female). Indeed, Sykes points out that physical education appears stuck in a binary conversation that focuses on the debate over single sex or coed classes. The notions of gendered and inclusive spaces that this debate evokes should lead to conversations around the need for safety for all students. Inclusive space suggests that scrutiny is less likely, but Sykes argues that 'the key pedagogy here is to confront the arbitrariness of the gender binary' (p. 45).

Chapter 4 is co-authored by Heather Sykes and Deborah McPhail, and is taken from their paper 'Unbearable lessons' (Sykes and McPhail, 2007). Concentrating on interview participants who self-identified as fat, their physical education experiences are presented as 'overwhelmingly negative, ranging from horrific and traumatic to incredulous and cynical' ( $\mathrm{p}$. 49). Like students of sexual and/or gender minorities experiencing marginalisation or erasure of their identities, fat or overweight students find it impossible to create a liveable fat subjectivity in this area of schooling' (p. 3). Themes of visibility, control, abjection and 
difference are re-established throughout the text. Fat is, Sykes and McPhail argue, presented as out of control and out of place, representing a lack of discipline. However, it is also presented here as a contestable discourse, against which students can reject physical education, or alternatively excel in sports and resist being seen as unable.

The participants in the qBody Project are all adults recalling their past physical education, meaning that they have a language with which they are able to articulate their identities that they may not have had during adolescence. Adult participants are also able to reflect on the lasting effect of their physical education experiences into their adult lives. Sykes states that interviewing adults enables more positive stories to emerge because the engagement of these adults in physical activity has changed since they were in school. Through this highlighting of positive relationships with one's body and physical activity, while remaining fat, Sykes is able to suggest inclusive pedagogies and curricular changes; participation in physical activity but also validation of diverse embodiment.

While Sykes highlights neoliberal policy in shaping educational environments, there is an underlying sense that often teachers may be enabling negative, marginalising experiences for some of their students. Part of the problem Sykes identifies is that those who become physical education students, on physical education teacher education (PETE) programmes, have a phantasy, from their childhoods, of enjoyment in physical education. Fear of 'the theft of its own enjoyment in the presence of queer bodies' (p. 98) is one of the origins of anxiety for physical education and the profession. Considering that the book is aimed at physical education practitioners, this is likely uncomfortable reading for educators. While asking what it means to be a good body in physical education, Sykes also asks whether the criteria by which physical education's success is measured, including enjoyment in movement, are enough. We can use the notion of queer to reconsider why enjoyment appears necessary in physical education even while anxiety remains common; why strong, positive movement is so often associated with injury and not with repair; and what ethics, health and fitness might mean:

Might queerness permit us to steal back some forms of movement, connection, community, stillness and unproductivity from the global, health and educational corporations? (p. 117).

The book closes with considering queer bodies' marginalisation and undervaluing within a physical education environment that aims to be fun and establish healthy lifelong physical activity, but which normalises certain ways of being and moving. Sykes asks, 'what is at stake in 'being good at physical education' (p. 105), tying this pertinent question to the physical education profession's focus on skilfulness and healthiness. Perhaps by sharing stories such as those in this book, physical education can be changed. Some of the participants suggested to the qBody Project interviewers that their stories could be sent out to teachers in schools or PETE programmes. In a way the book offers this, centring the participants' voices in ways that could be used by current students to reimagine physical education and gym spaces. In efforts to bring discussions of body image into schools, the experiences of the participants in this project can offer much to youth negotiating their bodies, 
selves and education. The participants' stories are difficult and 'heart-wrenching' (p. 60) to read but ultimately the focus is on students' agency to resist and reject normalising discourses. Among the painful accounts analysed here, there is also space for imaging alternatives. Sykes calls for individualised student learning; taking unequal social relations out of physical education experiences, including neoliberal perspectives on health and physical activity; and work to avoid tying the self and body to consumer choices and status.

I re-read this book amid post-London 2012 debates about the legacy of the Olympic games for both elite level sport and school physical education, with much being said about the games' success, calls for greater funding at grassroots and school levels, and claims for a refocus in schools on competitive (team game) sport. In these conversations the dual goals of success for elite sport and a population engaged in lifelong activity, the global celebration of the Olympics means that diverse narratives of less than successful PE experiences are rarely heard. In this climate, work such as Queer Bodies serves as a reminder of the others in sport and physical education discourse. This is a satisfying read for its focus on searching beyond links among physical education and normative (masculine and heterosexual) bodies. An articulate analysis, Queer Bodies represents taking back power from those who control physical education by understanding ways towards not just inclusion but decolonisation of physical education spaces and moving bodies by phantasies of normal bodies. Any move towards inclusion in physical education, school sport or physical activity needs to reach towards the deeper deconstruction of homophobia, transphobia and fatphobia that is found in Queer Bodies.

\section{References}

Sykes, H. and McPhail, D. 2007. Unbearable lessons: Contesting fat phobia in physical education. Sociology of Sport Journal, 25, 66-96.

Joanne Hill, Loughborough University 